\title{
Hva mener norske onkologer om sin arbeidssituasjon?
}

\author{
Sammendrag \\ Bakgrunn. Norsk onkologisk forening \\ mottok bekymringsmeldinger fra onko- \\ loger vedrørende arbeidssituasjonen \\ og ønsket derfor å kartlegge hvordan \\ leger som jobber med onkologi i Norge \\ opplever hverdagen.
}

Materiale og metode. Et spørreskjema ble sendt til alle spesialister og alle leger i spesialisering i onkologi. Skjemaet inneholdt bakgrunnsinformasjon om legene, hvordan de oppfattet sin arbeidssituasjon og hvilke tiltak de mente ville føre til bedre trivsel. Resultatene ble analysert med deskriptiv statistikk.

Resultater. 174 av 298 leger (58\%) svarte. Oppgitt median ukentlig totalarbeidstid var 52 timer for spesialister og 45 timer for leger i spesialisering. Henholdsvis $72 \%$ og $56 \%$ oppga at «arbeidsmengden er så stor at jeg har problemer å rekke alt». $63 \%$ av spesialistene mente jobben tok så mye energi at det gikk utover privatlivet, og $77 \%$ var «lite eller svært lite tilfreds» med tiden de hadde til rådighet til forskning. $54 \%$ av spesialistene og $72 \%$ av utdanningskandidatene var «svært tilfreds» eller «tilfreds» med jobben som helhet. Henholdsvis $86 \%$ og $61 \%$ av spesialistene mente at flere overlegestillinger eller utdanningsstillinger ville øke jobbtilfredsheten.

Fortolkning. Leger innen onkologi i Norge opplever at arbeidsbelastningen er for stor. Opprettelse av flere legestillinger, slik at tid kan frigjøres til faglig oppdatering og forskning, er et tiltak de mener vil bidra til å øke trivselen.

\section{Kirsten Marienhagen}

kirsten.marienhagen@unn.no

Kreftavdelingen

Universitetssykehuset Nord-Norge

9038 Tromsø

\section{Åslaug Helland}

Radiumhospitalet

Oslo universitetssykehus, Rikshospitalet

Terje Nordberg

Avdeling for kreftbehandling og medisinsk fysikk Haukeland universitetssykehus

\section{Marianne Grønlie Guren}

Kreftsenteret

Oslo universitetssykehus, Ullevål

Eva Hofsli

Kreftavdelingen

St. Olavs hospital

I flere internasjonale studier er det vist synkende jobbtilfredshet blant leger (1), men i studier fra Skandinavia har det vært gjennomgående høy grad av tilfredshet (2-4). I en norsk undersøkelse ble det påvist stabil og høy tilfredshet blant leger generelt, men det var forskjeller spesialitetene imellom $(2,3)$, samsvarende med en undersøkelse fra USA (5). Onkologi er en liten spesialitet, og er ikke med som egen gruppe i disse undersøkelsene.

Onkologer arbeider med medikamentell kreftbehandling og med strålebehandling i både kurativ og palliativ hensikt. Arbeidsbelastningen har økt betraktelig det siste tiåret. Kreftregisteret har beregnet at antall krefttilfeller vil øke med ca. 30\% frem mot 2020 . Det betyr at nesten 31000 nordmenn vil få kreft i 2020, i forhold til vel 24000 i 2006 (6). Den tumorrettede behandlingen, både kjemoterapi og strålebehandling, er blitt mer kompleks og ressurskrevende. I tillegg er det $ø k t$ fokus på lindrende behandling. I takt med bedret behandlingstilbud er det flere langtidsoverlevere som trenger oppfølging av onkolog $(6,7)$. Det er påkrevd med økt kunnskap om forebygging og håndtering av senfølger etter kreftbehandling.

Etter at styret i Norsk onkologisk forening (NOF) og spesialistkomiteen i onkologi mottok bekymringsmeldinger fra medlemmene vedrørende arbeidssituasjonen, besluttet styret å gjennomføre en spørreundersøkelse blant norske onkologer og leger under spesialisering i onkologi. Hensikten var å undersøke hvordan de opplevde arbeidssituasjonen og hvilke faktorer legene mente kunne føre til økt trivsel.

\section{Materiale og metode}

Styret i Norsk onkologisk forening utarbeidet et spørreskjema for å kartlegge arbeidsforholdene innen onkologi i Norge (8). Skjemaet ble laget ved å ta utgangspunkt $i$ andre undersøkelser om tilfredshet blant leger i Norge (2) og i Danmark (9). Klinisk forskningssenter ved Universitetssykehuset Nord-Norge bidro i utformingen av spørreskjemaet. Målgruppen var spesialister innen onkologi og assistentleger som jobbet under veiledning av onkolog (leger i spesialisering). Spørreskjemaet ble sendt til alle onkologer og til alle asssistentleger ved onkologiske avdelinger, poliklinikker eller strålesatellitter på Legeforeningens lister. Leger i forskningspermisjon og onkologer i administrative stillinger ble inkludert.

Skjemaet ble prøvd ut på et utvalg spesialister og utdanningskandidater før det i november 2006 ble sendt til 298 leger. Skjemaet var anonymisert. En purring ble sendt i januar 2007.

Del 1 av spørreskjemaet inneholdt spørsmål om legens bakgrunn, som alder, kjønn, utdanning, arbeidssted, stillingstype, arbeidsplan, overtid etc. «Ukentlig arbeidstid» var basert på tjenesteplanen og «total arbeidstid» var antall timer legene faktisk var på arbeid. I del 2 ble aspekter ved dagens arbeidssituasjon belyst, som jobbtilfredshet og arbeidets innvirkning på familieliv/privatliv. Forhold som kunne være med på å øke trivselen ble også kartlagt. De fleste spørsmålene i del 2 ble besvart på en fempunktsskala (svært tilfreds, tilfreds, både - og, lite tilfreds, svært lite tilfreds) (kvantitativ del), men det ble også stilt noen åpne spørsmål (kvalitativ del).

Deskriptive statistiske analyser ble utført ved hjelp av SPSS. Median og gjennomsnitt er presentert.

\section{Resultater}

174 av 298 leger svarte på spørreskjemaet $(58 \%)-83$ spesialister i onkologi og 91 leger i spesialisering. Det var 86 menn og 87

\section{Hovedbudskap}

- Leger innen onkologi opplever at arbeidspresset er stort

- Mer tid til faglig fordypning og forskning vil bidra til økt trivsel

- Det bør opprettes flere utdanningsog overlegestillinger innen onkologi 
Tabell 1 Informasjon om responderne i spørreundersøkelsen

\begin{tabular}{|c|c|c|}
\hline & $\begin{array}{c}\text { Spesialister } \\
\quad(n=83)\end{array}$ & $\begin{array}{c}\text { Leger } \\
\text { i spesialisering } \\
(\mathrm{n}=91)\end{array}$ \\
\hline Median alder (år) (spredning) & $49(35-67)$ & $33(27-50)$ \\
\hline Andel kvinner (\%) & 33 & 66 \\
\hline Andel som jobber ved universitetssykehus (\%) & 85 & 90 \\
\hline Median ukentlig arbeidstid ${ }^{1}(\mathrm{t})$ (gjennomsnitt) & $47(46)$ & $42(43)$ \\
\hline Median total arbeidstid ${ }^{1}$ (t) (gjennomsnitt) & $52(51)$ & $45(46)$ \\
\hline Andel med doktorgrad (\%) & 57 & 9 \\
\hline
\end{tabular}

kvinner (i ett tilfelle var kjønn ikke oppgitt). Øvrig informasjon om responderne finnes $\mathrm{i}$ tabell 1.

\section{Arbeidstid}

Median ukentlig arbeidstid i tjenesteplanen var 47 timer for spesialister og 42 timer for leger i spesialisering, mens oppgitt median total arbeidstid var henholdsvis 52 og 45 timer. Få spesialister fikk betalt for overtid utenom tjenesteplanen, mens de fleste av dem som var under spesialisering, fikk helt eller delvis betalt.

\section{Stilling}

$87 \%$ av spesialistene hadde fast overlegestilling. De hadde brukt gjennomsnittlig ti år fra autorisasjon som lege til spesialistgodkjenning (spredning 4-33 år). 20\% av spesialistene hadde en $20 \%$ bistilling, som oftest akademisk. Av leger i spesialisering oppga $96 \%$ at de hadde planer om å bli onkolog, og $64 \%$ var ansatt i fast utdanningsstilling.

\section{Jobbtilfredshet}

$54 \%$ av spesialistene og $72 \%$ av dem som var under spesialisering oppga at de var «tilfreds» eller «svært tilfreds» med jobben som helhet (tab 2). $46 \%$ av spesialistene var «tilfreds» eller «svært tilfreds» med den totale arbeidstiden, mens kun $22 \%$ var «tilfreds» eller «svært tilfreds» med arbeidsmengden generelt og kun $26 \%$ med mengden ikkeplanlagt overtid. Tallene for leger i spesialisering var noe høyere ( $\operatorname{tab} 2$ ).

Legene var godt fornøyd med variasjon i arbeidsoppgaver, typen arbeid og fysiske arbeidsforhold. I tillegg var de tilfredse med arbeidsmiljøet generelt, både hva gjelder forholdet til kollegene og til andre yrkesgrupper samt med mulighetene for å spørre kolleger til råds og få hjelp i vanskelige situasjoner (tab 2).

$31 \%$ av spesialistene var «lite eller svært lite tilfreds» med innflytelsen på organiseringen av arbeidsdagen (tab 2). Og henholdsvis $70 \%$ og $77 \%$ oppga at de var «lite eller svært lite tilfreds» med tiden de hadde til rådighet til faglig fordypning og forskning. Leger i spesialisering var mindre misfornøyd med tiden de hadde til fordypning, men $72 \%$ oppga at de var «lite eller svært lite tilfreds» med det de kunne bruke til forskning.

\section{Arbeidssituasjon}

$72 \%$ av spesialistene og $56 \%$ av dem som var under spesialisering var enige i utsagnet «arbeidsmengden er så stor at jeg har problemer med å rekke alt jeg bør få gjort i løpet av arbeidsdagen» (tab 3 ). $47 \%$ av spesialistene og $33 \%$ av utdanningskandidatene var enige i utsagnet «arbeidsmengden er så stor at jeg er redd for at det går utover kvaliteten på det jeg gjør».

\section{Privatliv}

Responderne syntes at arbeidet hadde innvirkning på privatlivet (tab 3 ). Flertallet spesialister mente at jobben tok så mye energi $(63 \%)$ og tid $(57 \%)$ at det gikk utover privatlivet. Tallene var noe lavere for leger $\mathrm{i}$ spesialisering.

\section{Trivselstiltak}

$86 \%$ av spesialistene og $75 \%$ av dem som var under spesialisering mente at flere overlegestillinger ville gi økt trivsel (tab 4). Færre avbrytelser ville øke trivselen for de fleste (tab 4). Henholdsvis $72 \%$ og $65 \%$ av spesialistene og $79 \%$ og $62 \%$ av dem som var under spesialisering ville ha trivdes bedre dersom de hadde hatt mer tid til faglig fordypning og forskning.

\section{Åpne spørsmål}

Den kvalitative delen av spørreundersøkelsen ble besvart av $86 \%$ (150/174). Mange påpekte et meget stort arbeidspress. "Altfor tøff arbeidsbelastning både fysisk og psykisk», «kronisk underbemanning over lang tid», «jobben tar all energi» og «det går kun rundt fordi noen jobber $150 \%$, var noen av kommentarene. Flere kom med faglige bekymringer, f.eks. «manglende tid til fagutvikling og forskning, som fører til nedprioritering av faget». Videre ble manglende autonomi, lite forutsigbarhet og dårlig organisering nevnt.

Det var imidlertid bred enighet blant responderne om at onkologi var et meget spennende, inspirerende og utfordrende fag. Spesielt ble variasjon i arbeidsoppgaver, fagets tverrfaglighet og det å ha en «me-

Tabell 2 Grad av tilfredshet med jobbsituasjonen for norske onkologer (\%)

\begin{tabular}{|c|c|c|c|c|c|c|}
\hline \multirow[b]{2}{*}{ Tilfredshet med jobbsituasjonen } & \multicolumn{2}{|c|}{$\begin{array}{l}\text { «Svært tilfreds» } \\
\text { eller «tilfreds» }\end{array}$} & \multicolumn{2}{|c|}{ «Både - og» } & \multicolumn{2}{|c|}{$\begin{array}{l}\text { «Lite tilfreds» eller } \\
\text { «svært lite tilfreds» }\end{array}$} \\
\hline & Spesialister & $\begin{array}{c}\text { Leger } \\
\text { i spesialisering }\end{array}$ & Spesialister & $\begin{array}{c}\text { Leger } \\
\text { i spesialisering }\end{array}$ & Spesialister & $\begin{array}{c}\text { Leger } \\
\text { i spesialisering }\end{array}$ \\
\hline Jobben som helhet (\%) & 54 & 72 & 37 & 25 & 9 & 3 \\
\hline Total arbeidstid (\%) & 46 & 65 & 33 & 28 & 21 & 7 \\
\hline Arbeidsmengde generelt (\%) & 22 & 43 & 27 & 31 & 51 & 26 \\
\hline Ikke-planlagt overtid (\%) & 26 & 40 & 20 & 26 & 54 & 34 \\
\hline Variasjon i oppgavene (\%) & 77 & 58 & 22 & 27 & 1 & 15 \\
\hline Relasjon til kolleger (\%) & 92 & 97 & 8 & 2 & 0 & 1 \\
\hline Relasjon til andre yrkesgrupper (\%) & 81 & 82 & 18 & 18 & 1 & 0 \\
\hline Mulighet for å spørre om råd (\%) & 89 & 92 & 7 & 8 & 4 & 0 \\
\hline Mulighet å få hjelp i vanskelige situasjoner (\%) & 80 & 83 & 15 & 17 & 5 & 0 \\
\hline Innflytelse (\%) & 32 & 26 & 37 & 53 & 31 & 21 \\
\hline Tid til fordypning $(\%)$ & 9 & 21 & 21 & 26 & 70 & 53 \\
\hline Tid til forskning (\%) & 8 & 10 & 15 & 18 & 77 & 72 \\
\hline
\end{tabular}


ningsfull jobb» vektlagt. Mange nevnte et svært godt arbeidsmiljø med hyggelige kolleger/kollegial støtte samt givende pasientkontakt som noen av årsakene til trivselen.

\section{Diskusjon}

Norsk onkologi står overfor store utfordringer - med forventet ekspansjon volum-, kunnskaps- og kostnadsmessig. Resultatene fra spørreundersøkelsen viser tydelig at flertallet av legene innen faget opplever at tiden ikke strekker til og at arbeidspresset er for stort. Selv om spørsmålene ikke er de samme som i undersøkelser om jobbtilfredshet blant norske leger generelt (2) og direkte sammenlikning derfor ikke er mulig, kan resultatene tyde på at tilfredsheten er lavere hos onkologene enn hos norske leger generelt.

En svakhet ved studien er at svarprosenten er noe lav (58\%). Det er mulig at holdningen hos dem som ikke svarte er en annen enn respondernes, men vi mener at tallene og utsagnene som fremkommer uansett vitner om stort arbeidspress for leger innen onkologi. Stor arbeidsbelastning kan føre til mistrivsel og frustrasjon hos arbeidstakere, og arbeidsbelastning, rekruttering og stabilitet $\mathrm{i}$ bemanningen kan bli en ond sirkel (1).

En spørreundersøkelse om arbeidsforholdene for yngre leger ved onkologiske avdelinger i Danmark viste at disse var mer stresset enn normalbefolkningen (10). Kvinnelige leger fant det psykiske arbeidsmiljøet mer belastende og mer utilfredsstillende enn sine mannlige kolleger. Vår undersøkelse viste imidlertid ingen kjønnsforskjell når det gjaldt opplevelse av arbeidssituasjonen.

Utenlandske studier har vist at leger innen onkologi opplever høy grad av «psykisk utmattelse». I en engelsk studie fra 2005 hadde rundt $50 \%$ av onkologene en følelse av utbrenthet (11). Andelen var signifikant høyere i 2005 enn i 1994. Blant radiologer og gastroenterologer ble det ikke påvist noen tilsvarende økning i tidsperioden. Undersøkelser viser at også innen onkologisk kirurgi er det en høy andel leger (30\%) som har opplevd utbrenthet (12). Man kan spekulere på om risikoen for utbrenthet er høyere i yrker der man møter liv-død-spørsmål. Vi har ut fra vår undersøkelse ingen tall om utbrenthet blant onkologer, men resultatene, som tyder på at arbeidet går utover fritid og familieliv, er bekymringsfulle.

Legene i undersøkelsen peker på at opprettelse av flere overlege- og assistentlegestillinger vil gi et bedre arbeidsmiljø. Ifølge høringsdokumentet Utredning om spesialistutdanning av leger fra Den norske legeforening i 2007 måtte man, for å etterkomme en forventet etterspørselvekst på 9\%, øke antallet spesialistgodkjenninger $\mathrm{i}$ onkologi til 26 per år (mot 9,2 per år i perioden 2002-07) (13). En slik opptrapping av utdanningskapasiteten i onkologi haster, og den må planlegges og organiseres slik at den blir gjennomførbar. Med en gjennomsnittlig utdanningstid på 8,3 år (14) vil økt utdan-

Tabell 3 Norske onkologers oppfatning av arbeidsmengde og hvordan jobben påvirker privatlivet. Andel spesialister og leger i spesialisering som svarer at følgende utsagn «passer svært godt» eller «passer godt» $(\%)$

\begin{tabular}{|c|c|c|}
\hline & $\begin{array}{l}\text { Spesialister } \\
(\%)\end{array}$ & $\begin{array}{c}\text { Leger } \\
\text { i spesialisering (\%) }\end{array}$ \\
\hline «Arbeidsmengden er så stor at jeg har problemer å rekke alt» & 72 & 56 \\
\hline $\begin{array}{l}\text { «Arbeidsmengden er så stor at jeg er redd for at det går } \\
\text { utover kvaliteten» }\end{array}$ & 47 & 33 \\
\hline $\begin{array}{l}\text { «Jobben tar så mye av min energi at det går utover } \\
\text { mitt privatliv» }\end{array}$ & 63 & 39 \\
\hline «Jobben tar så mye av min tid at det går utover mitt privatliv» & 57 & 41 \\
\hline
\end{tabular}

Tabell 4 Faktorer som norske onkologer mener har betydning for trivselen (\%)

\begin{tabular}{lcc} 
& Spesialister (\%) & Leger i spesialisering (\%) \\
\hline Flere overlegestillinger & 86 & 75 \\
\hline Flere utdanningsstillinger & 61 & 65 \\
\hline Færre avbrytelser & 75 & 65 \\
Mer tid til faglig oppdatering & 72 & 79 \\
Mer tid til forskning & 65 & 62 \\
\hline Sterkere nasjonale retningslinjer & 23 & 31 \\
\hline Mer tid til lunsj med kolleger & 44 & 50 \\
\hline Mindre økonomiske hensyn i behandlingsvalg & 20 & 20
\end{tabular}

ningskapasitet ikke gi resultater før etter flere år.

Norske myndigheter har i «kreftstrategien» (Nasjonal strategi for kreftområdet 2006-2009) lagt frem et ønske om å «legge til rette for bedre kvalitet og kompetanse, tilstrekkelig kapasitet og likeverdig tilgjengelighet» innen kreftomsorgen (15). Dette skal oppnås ved å opprettholde onkologi som en av de prioriterte spesialitetene. Legene i vår undersøkelse peker på at mer tid til faglig fordypning og forskning er viktig for å bedre arbeidsforholdene og for at at pasientene skal være sikret moderne og god kreftbehandling.

Vår spørreundersøkelse viser at legene innen onkologi synes det er et stort gap mellom arbeidsoppgaver og legeressurser, noe som gir grunn til bekymring. Trivselen betyr mye for at de som arbeider innen onkologien skal forbli i sine stillinger. Resultatene fra spørreundersøkelsen viser til viktige og praktisk gjennomførbare tiltak som kan bidra til at ferdig utdannede spesialister fortsetter i sine kliniske stillinger og til at utdanningskandidatene fullfører spesialistutdanningen. Dette er viktig for å sikre god kvalitet i kreftomsorgen $\mathrm{i}$ årene fremover.

Oppgitte interessekonflikter: Ingen

Litteratur

Zuger A. Dissatisfaction with medical practice. N Engl J Med 2004; 350: 69-75.

2. Nylenna M, Gulbrandsen P. Forde R et al. Job satisfaction among Norwegian general practitioners. Scand J Prim Health Care 2005; 23: 198-202.

3. Nylenna M, Gulbrandsen P. Forde R et al. Unhappy doctors? A longitudinal study of life and job satisfaction among Norwegian doctors 1994-2002. BMC Health Serv Res 2005; 5: 44
Bergin $\mathrm{E}$, Johansson $\mathrm{H}$, Bergin R. Are doctors unhappy? A study of residents with an open interview form. Qual Manag Health Care 2004; 13 $81-7$

5. Leigh JP, Kravitz RL, Schembri M et al. Physician career satisfaction across specialties. Arch Intern Med 2002; 162: 1577-84

6. Kreftregisteret: Cancer in Norway 2006. Krefttrender. www.kreftregisteret.no/no/Generelt/ Fakta-om-kreft/Krefttrender/ (2.6.2009).

7. Kreftregisteret. Cancer i Norway 2006. www.kreftregisteret.no/Generelt/Publikasjoner/ Cancer-in-Norway/Cancer-in-Norway-2006/ (2.6.2009).

8. Spørreskjema: Arbeidsforhold for onkologer i Norge. www.legeforeningen.no/id/147182.0 (26.8.2009).

9. Det lange forskerspørgeskema om psykisk arbejdsmiljø.Det Nasjonale Forskningscenter for Arbeidsmiljø. www.arbejdsmiljoforskning.dk/ (2.6.2009).

10. Wieclaw J, Paludan M, Rosenkilde M et al. Psykisk arbejdsmiljø blandt yngre læger på onkologiske afdelinger. Et spørgeskemabasert tværsnitsstudie. Ugeskr Læger 2008; 170: 536-40.

11. Taylor C, Graham J, Potts HW et al. Changes in mental health of UK hospital consultants since the mid-1990s. Lancet 2005; 366: 742-4.

12. Kuerer HM, Eberlein TJ, Pollock RE et al. Career satisfaction, practice patterns and burnout among surgical oncologists: report on the quality of life of members of the Society of Surgical Oncology. Ann Surg Oncol 2007; 14: 3043-53.

13. Interne høringer. Høringsdokument: Utredning om spesialistutdanning av leger 2007. Oslo: Den norske legeforening, 2008: 78, 84. www.legeforeningen.no/index.gan?id=137138 (2.6.2009).

14. Skoglund E. Godkjente spesialister i 2008. Tidsskr Nor Legeforen 2009; 129: 328-9.

15. Nasjonal strategi for kreftområdet 2006-2009, side 6-7. www.regjeringen.no/nb/dep/hod/tema/ sykehus/Nasj_strat kreftomr.html?id=115233 (2.6.2009).

Manuskriptet ble mottatt 26.9. 2008 og godkjent 14.1. 2010. Medisinsk redaktør Trine B. Haugen. 